\title{
Box lesion in the open left atrium for surgical ablation of atrial fibrillation
}

\author{
Leonid Sternik, MD, ${ }^{\mathrm{a}}$ Alexander Kogan, MD, ${ }^{\mathrm{a}}$ David Luria, MD, ${ }^{\mathrm{b}}$ Michael Glikson, MD, ${ }^{\mathrm{b}}$ \\ Ateret Malachy, MA, ${ }^{a}$ Shany Levin, MA, ${ }^{a}$ and Ehud Raanani, MD $^{\mathrm{a}}$
}

\begin{abstract}
Objective: Cut-and-sew maze with a box lesion around the pulmonary veins is currently the criterion standard procedure for surgical ablation of atrial fibrillation. Recently, we changed our technique from standard bilateral epicardial pulmonary vein isolation with interconnecting lesions to a box lesion procedure with a bipolar radiofrequency ablation device. Our study describes this technique.
\end{abstract}

\begin{abstract}
Methods: Between March 2009 and June 2012, we performed 90 ablations by the box technique with a bipolar radiofrequency device. Fifty-five patients $(61 \%)$ had persistent atrial fibrillation, and $21(23 \%)$ had longstanding persistent atrial fibrillation. The left atriotomy was performed along the interatrial septum and the left atrial appendage amputated. The box was made by connecting the left atriotomy to the base of the amputated appendage with lines along the transverse and oblique sinuses by epicardial and endocardial application of a bipolar radiofrequency ablation device. The left atrial isthmus was ablated by cryoprobe.
\end{abstract}

Results: There were no ablation-related complications. The box was easy to perform, with no dissection around the pulmonary veins. At 6-month, 1-year, and 2-year follow-ups, 80 (94\%), 69 (93\%), and $47(91 \%)$ patients, respectively, were in sinus rhythm. Freedoms from antiarrhythmic medications in patients in sinus rhythm at 6 months, 1 year, and 2 years were $78 \%, 88 \%$, and $85 \%$, respectively.

Conclusions: The box lesion provided excellent freedom from atrial fibrillation and may improve transmurality through ablation of 1 rather than 2 layers of atrial wall, as in epicardial pulmonary vein isolation. With the box lesion, dissection around the pulmonary veins is unnecessary. (J Thorac Cardiovasc Surg 2014;147:956-9)

In recent years, both the development of new energy sources for ablation and new complex, effective lesion patterns have transformed surgical ablation of atrial fibrillation into a widely performed operative procedure. Bipolar radiofrequency (RF) ablation with bilateral epicardial pulmonary vein isolation is among the most important elements of these new techniques. ${ }^{1-5}$ Nevertheless, the classic cut-andsew maze procedure still provides the best results with respect to freedom from atrial fibrillation. The most important lesion in the left atrium in the maze III procedure is probably the box lesion around the pulmonary veins. ${ }^{6-10}$ In this report, we describe our experience with a box lesion made in the open left atrium with a bipolar RF ablation device.

\section{MATERIALS AND METHODS}

Between March 2009 and June 2011, left atrial surgical ablation was performed in 90 patients with our box technique with a bipolar RF device

From the Department of Cardiac Surgery ${ }^{\mathrm{a}}$ and the Heart Institute, ${ }^{\mathrm{b}}$ Chaim Sheba Medical Center, Tel Hashomer, and the Sackler Faculty of Medicine, Tel Aviv University, Tel Aviv, Israel.

Disclosures: Authors have nothing to disclose with regard to commercial support.

Received for publication Dec 12, 2012; revisions received Jan 22, 2013; accepted for publication Feb 12, 2013; available ahead of print March 13, 2013.

Address for reprints: Leonid Sternik, MD, Department of Cardiac Surgery, Chaim Sheba Medical Center, Tel Hashomer, 52621, Israel (E-mail: Leonid.Sternik@ sheba.health.gov.il).

0022-5223/\$36.00

Copyright (c) 2014 by The American Association for Thoracic Surgery

http://dx.doi.org/10.1016/j.jtcvs.2013.02.027
(Cardioblate 2; Medtronic Inc, Minneapolis, Minn), with the addition of a cryoprobe (Frigitronics; Cooper Surgical, Trumbull, Conn). Procedures were performed by 2 surgeons (L.S. and E.R.).

All data for this study were obtained from the cardiac surgery department's database and were retrieved with the approval of our institutional review board, which waived the need for patient consent because individual patients were not identified. Each patient signed an informed consent form before surgery, and all ablation procedure details were explained to each patient. The preoperative patient characteristics are detailed in Table 1.

\section{Operative Technique}

We performed the same ablation procedure for all patients. All patients underwent an ablation procedure through a midsternotomy incision under cardioplegic arrest. The ablation was limited to the left atrium. The following ablation devices were used: a bipolar RF device (Cardioblate 2) and a cryoprobe (Frigitronics). To perform a box lesion, we opened the left atrium along the interatrial groove, following the accepted approach used for mitral valve surgery. The left atrial appendage was amputated, after which we made a dissection around the superior and inferior venae cavae to reach the transverse and oblique pericardial sinuses. After this dissection was complete, we placed a jaw of a bipolar RF ablation device epicardially and placed the other jaw of the clamp endocardially, performing ablation lines in the left atrium along the transverse and then the oblique sinuses. These 2 lines connected the atriotomy incision and the left atrial appendage stump. In cases in which the left atrium was enlarged, resulting in a bipolar clamp that was not long enough to reach the appendage stump along the oblique sinus line, we applied a bipolar RF clamp from the open stump of the left atrial appendage to complete the oblique sinus ablation line. In this way, the oblique sinus line made by RF ablation was angulated. This placement allowed narrowing down in a wedge shape of the isolated posterior portion of the left atrium. We were concerned that a problem with left atrial contractility might develop if the isolated posterior portion was too large. 


\section{Abbreviation and Acronym \\ $\mathrm{RF}=$ radiofrequency}

The upper and lower lines of the box lesion thus included the bipolar RF epicardial and endocardial lesion in the left atrial roof, along the transverse sinus, and a lesion along the oblique sinus. The right and left sides of the box lesion included the left atriotomy incision along the interatrial septum, and an incision left by the amputated left atrial appendage ${ }^{11}$ (Figure 1). In all cases we added a left atrial isthmus line, which was made with a bipolar $\mathrm{RF}$ device and a cryoprobe, and closed the stump of the removed left atrial appendage with 2 layers of running 5-0 suture. Surgical data are presented in Table 2.

\section{Postoperative Care and Follow-up}

Atrial and ventricular pacing wires were placed in all patients at surgery. Atrial pacing was performed wherever possible to prevent atrial ectopic activity, which could potentially revert to atrial fibrillation. Amiodarone was administered only in cases of postoperative atrial fibrillation and not as a prophylactic treatment. Electrical cardioversion was attempted in cases of continuous atrial fibrillation lasting longer than 48 hours before hospital discharge; if necessary, it was also performed at 3 months after the surgery. Oral anticoagulation (warfarin) treatment was started on the first postoperative day and was continued for at least 3 months, depending on the type of surgery, the patient's heart rhythm, and the left atrial contractility. ${ }^{12}$ During hospitalization, continuous electrocardiographic monitoring (telemetry) was performed on all patients. All electrocardiographic changes, recorded in real time, were stored in the monitor's memory. The follow-up, which was complete in terms of clinical and cardiac rhythm status, was $402 \pm 258$ days (median, 385 days; range, 85-912 days). All patients were seen by a surgeon at 1 month after discharge and then by an electrophysiologist at 3, 6, and 12 months after surgery and every 6 months thereafter. Twenty-four-hour Holter electrocardiographic monitoring was performed in all patients at either 3 or 6 months after the operation and then at 1 year after surgery and thereafter as needed but at least once a year. If a patient reported symptoms, Holter monitoring was performed immediately. All medical data from visits to any medical facilities concerning the patients' heart rhythm were also recorded. Echocardiography was performed at 6 months after surgery. Any adverse cardiovascular events were recorded.

\section{RESULTS}

There were no perioperative or late deaths. Two patients had a postoperative cerebrovascular accident occur. These patients did not emerge satisfactorily from anesthesia, and a computed tomographic scan revealed an ischemic brain infarction in each case. Later these patients had neurologic improvement, with one recovering completely and the other nearly completely.

The mean intensive care unit stay was 2 days (range 1-4 days), and mean hospitalization was 7 days (range 5-11 days). Eighty-five patients (94\%) were discharged in sinus rhythm. At 6 months, 1 year, and 2 years of follow-up, 80 patients (94\%), 69 patients (93\%), and 47 patients (91\%), respectively, were in sinus rhythm. Additional data regarding early and midterm follow-up, including anticoagulation and antiarrhythmic medications, appear in Tables 3 and 4, respectively.
TABLE 1. Preoperative patient characteristics

\begin{tabular}{lc}
\hline Age $(y$, mean \pm SD) & $63 \pm 10$ \\
Male & $59(65 \%)$ \\
New York Heart Association functional class & \\
I-II & $63(70 \%)$ \\
III-IV & $27(30 \%)$ \\
Atrial fibrillation type & \\
$\quad$ Paroxysmal & $14(16 \%)$ \\
Persistent & $55(61 \%)$ \\
Long-standing persistent & $21(23 \%)$ \\
Atrial fibrillation duration $(y$, mean \pm SD) & $5.4 \pm 9$ \\
$<1$ & $20(22 \%)$ \\
$1-5$ & $34(38 \%)$ \\
$5-10$ & $24(27 \%)$ \\
$>10$ & $12(13 \%)$ \\
Echocardiographic data & \\
Left atrial volume $(m L$, mean \pm SD) & $136 \pm 55$ \\
Left atrial volume $>200 \mathrm{~mL}$ & $11(12 \%)$ \\
Left ventricular function & \\
$\quad$ Normal & $83(92 \%)$ \\
$\quad$ Mild dysfunction & $4(5 \%)$ \\
$\quad$ Moderate dysfunction & $3(3 \%)$ \\
Severe dysfunction & $0(0 \%)$ \\
Ejection fraction $(\%$, mean $\pm \mathrm{SD})$ & $55 \% \pm 9 \%$ \\
\hline
\end{tabular}

Data represent number and percentage of patients except as marked. $S D$, Standard deviation.

\section{DISCUSSION}

The classic cut-and-sew maze III procedure provides excellent results, with more than $90 \%$ freedom from atrial fibrillation. ${ }^{1-3}$ The most important lesion in the maze III procedure is probably the box lesion located around the pulmonary veins. ${ }^{6-8}$ The importance of isolating the pulmonary veins is clear from Haissaguerre and colleagues' classic study, ${ }^{9}$ which shows that most atrial fibrillation originates from the pulmonary veins. ${ }^{10}$ The maze III procedure has not been widely adopted by surgeons, however, because of its technical complexity. Recently, devices that use alternative energy sources have been developed for surgical ablation of atrial fibrillation. $^{1-5,9}$ One of the most widely used modern devices for atrial fibrillation surgery is the bipolar RF ablation device. This device is mostly applied for epicardial bilateral

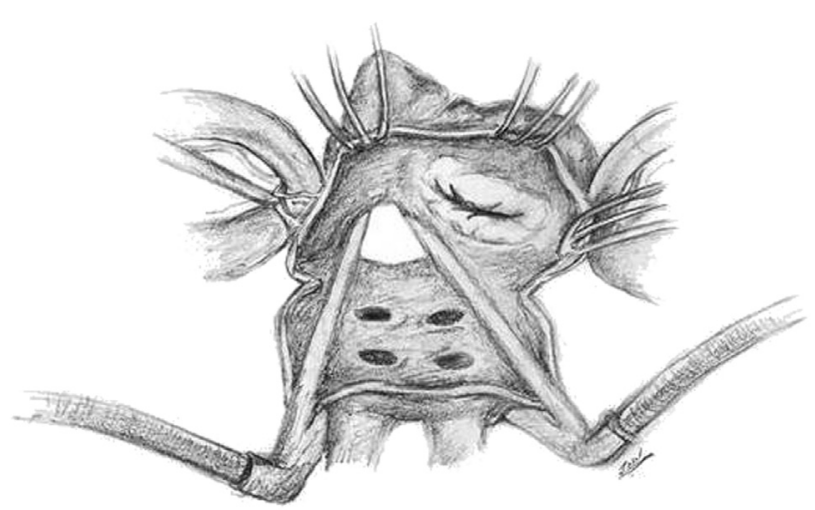

FIGURE 1. Box lesion with bipolar radiofrequency ablation device. 
TABLE 2. Operations

\begin{tabular}{lc}
\hline Mitral repair & $29(32 \%)$ \\
Mitral replacement & $26(29 \%)$ \\
Nonmitral surgery & $35(39 \%)$ \\
$\quad$ Coronary artery bypass grafting & $22(24 \%)$ \\
$\quad$ Aortic valve replacement & $11(13 \%)$ \\
$\quad$ Septal myectomy & $2(2 \%)$ \\
Crossclamp time (min, mean \pm SD) & $95 \pm 28$ \\
Cardiopulmonary bypass time (min, mean \pm SD) & $118 \pm 32$ \\
\hline Data represent number and percentage of patients except as marked. SD, Standard \\
deviation.
\end{tabular}

pulmonary vein isolation. The principal part of the various lesion sets performed with the bipolar RF ablation device is epicardial bilateral pulmonary vein isolation, usually with the addition of an interconnecting lesions and a left atrial isthmus line. ${ }^{4,9,13}$

It should be noted that some shortcomings exist with regard to the use of epicardial pulmonary vein isolation with a bipolar RF device. To apply the ablation device, it is necessary to dissect around the pulmonary veins. This dissection could be both difficult and dangerous in the presence of aberrant pulmonary veins and also in cases of cardiomegaly, left ventricular hypertrophy, severe mitral annular calcification, and reoperative procedure. In such cases, heart elevation for left pulmonary vein exposure could be complicated. The dissection needed for the box lesion as we perform it is the only dissection around the superior and inferior venae cavae to open the transverse and oblique sinuses. This dissection is easier than dissecting around the pulmonary veins and does not require the left ventricular elevation that is needed to reach the left pulmonary veins. As a result, the technique described in this article seems to be simpler than bilateral epicardial pulmonary vein isolation, which is the technique currently used by most surgeons. On the basis of the simplicity of this technique, we believe that it could be adopted widely, rather than confined to tertiary referral centers.

We believe that bipolar epicardial pulmonary vein isolation may not always be transmural. Left atrial wall

\section{TABLE 3. Early postoperative data}

\begin{tabular}{lc}
\hline Mortality & $0(0 \%)$ \\
Cerebrovascular accident & $2(2 \%)$ \\
Myocardial infarction & $0(0 \%)$ \\
Ventilation $(\mathrm{h}$, mean $\pm \mathrm{SD})$ & $30 \pm 90$ \\
Ventilation $>48 \mathrm{~h}$ & $8(9 \%)$ \\
Renal failure & $6(7 \%)$ \\
Wound infection & $2(3 \%)$ \\
Rhythm at discharge & \\
$\quad$ Sinus & $85(94 \%)$ \\
$\quad$ Atrial fibrillation or flutter & $4(5 \%)$ \\
$\quad$ Nodal & $1(1 \%)$ \\
Permanent pacemaker & $1(1 \%)$ \\
\hline Data represent number and percentage of patients except as marked. SD, Standard \\
deviation.
\end{tabular}

TABLE 4. Midterm results

\begin{tabular}{lccc}
\hline & $\begin{array}{c}\mathbf{6} \mathbf{~ m o} \\
(\mathbf{N}=\mathbf{8 5})\end{array}$ & $\begin{array}{c}\mathbf{1} \mathbf{y} \\
(\mathbf{N}=\mathbf{7 4})\end{array}$ & $\begin{array}{c}\mathbf{2 ~ y} \\
(\mathbf{N}=\mathbf{5 3})\end{array}$ \\
\hline Sinus & $80(94 \%)$ & $69(93 \%)$ & $48(91 \%)$ \\
Atrial fibrillation or flutter & $5(6 \%)$ & $5(7 \%)$ & $5(9 \%)$ \\
$\begin{array}{l}\text { Freedom from atrial } \\
\quad \text { fibrillation and AAD }\end{array}$ & $67(78 \%)$ & $65(88 \%)$ & $45(85 \%)$ \\
$\begin{array}{l}\text { Sinus rhythm without warfarin } \\
\text { Data represent number and percentage of patients. }\end{array}$ & $26(30 \%)$ & $34(46 \%)$ & $32(60 \%)$ \\
treatment. Anti-arrhythmic drug
\end{tabular}

thickness can reach 4 to $5 \mathrm{~mm}$. When we apply the bipolar ablation device epicardially, we clamp 2 layers of atrial wall. Ablation of 8 to $10 \mathrm{~mm}$ of tissue thickness may not achieve transmurality. Golovchiner and associates ${ }^{14}$ have stated that a loss of transmurality could cause left atrial flutter, which is very difficult to treat. Some surgeons perform epicardial pulmonary vein isolation with a single interconnecting lesion. We believe, however, that complete isolation of the whole area around the pulmonary veins by a box lesion may be the preferred option. Schmitt and coworkers ${ }^{15}$ and Lee and colleagues ${ }^{16}$ showed that there are many sources of arrhythmia in cases of left atrial enlargement related to mitral valve disease, not only the pulmonary vein ostia. Lee and colleagues ${ }^{16}$ further stated that the left atrial posterior wall becomes one of the most important sources of atrial fibrillation in dilated atria. Voeller and associates ${ }^{17}$ found that a box lesion isolating the entire posterior left atrium improves ablation outcome relative to that achieved with pulmonary vein isolation with a single interconnecting lesion.

Some surgeons perform pulmonary vein isolation with 2 interconnecting lesions, making a box lesion. ${ }^{9,13}$ In such cases, pulmonary vein isolation seems unnecessary because the box lesion itself isolates the pulmonary veins. Furthermore, unnecessary epicardial lesion lines, ablating 2 layers of atrial wall around the pulmonary veins, may not be completely transmural, particularly with a thick atrial wall, and thus could cause left atrial flutter.

There are many descriptions in the literature of box lesions performed with various energy sources. Epicardial box lesions around pulmonary veins have been performed with a microwave ablation device (FLEX 10 AFx Microwave Ablation System; Guidant, Indianapolis, Ind), ${ }^{17,18}$ an RF device (Cobra Adhere XL; Estech, San Ramon, Calif), ${ }^{19,20}$ and an ablation device that used high-intensity focused ultrasound (Epicor; St Jude Medical, Sunnyvale, Calif). ${ }^{21}$ With respect to microwave ablation devices, Melby and coworkers ${ }^{18}$ found no reliable transmural lesion and discovered that transmurality strongly depended on the extent of cardiac output. ${ }^{18}$ Pruitt and associates ${ }^{19}$ reported that only $42 \%$ of patients were in normal sinus rhythm at the end of follow-up after microwave epicardial ablation. Bevilacqua and associates ${ }^{20}$ described an initial experience with a novel monopolar RF device to create a box lesion 
(Cobra Adhere XL). On the other hand, Miyagi and colleagues ${ }^{22}$ reported that epicardial monopolar RF ablation does not produce a transmural lesion and a conduction block. In a recent article, McCarthy and associates ${ }^{21}$ reported poor results of ablation with high-intensity focused ultrasound, with only $43 \%$ of patients in normal sinus rhythm. We therefore judge that monopolar devices applied epicardially to create a box lesion do not produce a reliable transmural lesion and thus are not sufficiently effective.

In our experience, we obtained excellent results with our box lesion technique performed on the arrested heart and opened left atrium. We performed the same ablation procedure for all patients. We were comfortable with this procedure and also considered it easier to draw conclusions when performing the same procedure in the various patient groups. The results remained excellent both at discharge and at 6 months, 1 year, and 2 years of follow-up. We believe that we can attribute this high success rate to the better transmurality of the lesions with our box technique.

\section{Study Limitations}

Follow-up in this study was limited to 2 years, and the sample was also limited. A larger patient cohort and longer follow-up are both needed to substantiate further the advantages of this technique.

We did not perform any intraoperative conduction testing at the end of surgery. We performed all procedures, including ablation, on the arrested heart, and conduction tests may be less reliable after cardioplegic arrest. In addition, we believe that a finding of no conduction immediately after ablation does not necessarily guarantee a transmural lesion 6 months after surgery.

Many authors have advocated a biatrial procedure. Our experience, however, is similar to that reported by Soni and colleagues, ${ }^{23}$ who also found a left atrial procedure to be efficient and to carry a low procedural morbidity. In the past, we performed biatrial procedures with a different technique in some patients. Results were not as good, although the patient population was different, making a comparison difficult.

We tried to find risk factors for failure to achieve freedom from atrial fibrillation and antiarrhythmic drugs. The limited number of failures probably prevented us from finding such risk factors.

\section{CONCLUSIONS}

We conclude that a box lesion performed with an RF device on the arrested heart with the left atrium open may be a promising technique for the surgical ablation of atrial fibrillation. Study for an extended follow-up period with a larger group of patients is warranted to establish the possible long-term advantages of this technique.

We thank Vivienne York for her valuable English language editing.

\section{References}

1. Gillinov AM, Blackstone EH, McCarthy PM. Atrial fibrillation: current surgical options and their assessment. Ann Thorac Surg. 2002;74:2210-7.

2. Sie HT, Beukema WP, Ramdat Misier AR, Elvan A, Ennema JJ, Wellens HJ. The radiofrequency modified maze procedure. A less invasive approach to atrial fibrillation during open-heart surgery. Eur J Cardiothorac Surg. 2001; 19:442-7.

3. Williams MR, Stewart JR, Bolling SF, Freeman S, Anderson JT, Argenziano M, et al. Surgical treatment of atrial fibrillation using radiofrequency energy. Ann Thorac Surg. 2001;71:1939-43; discussion 1943-4.

4. Benussi S, Nascimbene S, Calori G, Denti P, Ziskind Z, Kassem S, et al. Surgical ablation of atrial fibrillation with a novel bipolar radiofrequency device. J Thorac Cardiovasc Surg. 2005;130:491-7.

5. Gammie JS, Didolkar P, Krowsoski LS, Santos MJ, Toran AJ, Young CA, et al. Intermediate-term outcomes of surgical atrial fibrillation correction with the CryoMaze procedure. Ann Thorac Surg. 2009;87:1452-8; discussion 1458-9

6. Cox JL, Schuessler RB, D'Agostino HJ Jr, Stone CM, Chang BC, Cain ME, et al. The surgical treatment of atrial fibrillation. III. Development of a definitive surgical procedure. J Thorac Cardiovasc Surg. 1991;101:569-83.

7. Cox JL. The surgical treatment of atrial fibrillation. IV. Surgical technique. J Thorac Cardiovasc Surg. 1991;101:584-92.

8. Schaff HV, Dearani JA, Daly RC, Orszulak TA, Danielson GK. Cox-Maze procedure for atrial fibrillation: Mayo Clinic experience. Semin Thorac Cardiovasc Surg. 2002;12:30-7.

9. Haissaguerre M, Jaïs P, Shah DC, Takahashi A, Hocini M, Quiniou G, et al. Spontaneous initiation of atrial fibrillation by ectopic beats originating in the pulmonary veins. N Engl J Med. 1998;339:659-66.

10. Sternik L, Ghosh P, Luria D, Glikson M, Shpigelshtein D, Malachy A, et al. Midterm results of the 'hybrid maze': a combination of bipolar radiofrequency and cryoablation for surgical treatment of atrial fibrillation. $J$ Heart Valve Dis. 2006;15:664-70

11. Sternik L, Schaff HV, Luria D, Glikson M, Kogan A, Malachy A, et al. Left atrial ablation for atrial fibrillation: "box lesion" with bipolar radiofrequency device. Tex Heart Inst J. 2011;38:127-31.

12. Buber Y, Luria D, Sternik L, Raanani E, Feinberg MS, Gurevich O, et al. Left atrial function after the Maze procedure and the occurrence of thromboembolic stroke. J Am Coll Cardiol. 2011;57(14 Suppl 1):E1355.

13. Gillinov M. Choice of surgical lesion set: answers from data. Ann Thorac Surg 2007;84:1786-92.

14. Golovchiner G, Mazur A, Kogan A, Strasberg B, Shapira Y, Fridman M, et al. Atrial flutter after surgical radiofrequency ablation of the left atrium for atrial fibrillation. Ann Thorac Surg. 2005;79:108-12.

15. Schmitt C, Ndrepepa G, Weber S, Schmieder S, Weyerbrock S, Schneider M et al. Biatrial multisite mapping of atrial premature complexes triggering onset of atrial fibrillation. Am J Cardiol. 2002;89:1381-7.

16. Lee SH, Tai CT, Hsieh MH, Tsao HM, Lin YJ, Chang SL, et al. Predictors of nonpulmonary vein ectopic beats initiating paroxysmal atrial fibrillation: implication for catheter ablation. J Am Coll Cardiol. 2005;46:1054-9.

17. Voeller RK, Bailey MS, Zierer A, Lall SC, Sakamoto S, Aubuchon K, et al. Isolating the entire posterior left atrium improves surgical outcomes after the Cox maze procedure. J Thorac Cardiovasc Surg. 2008;135:870-7.

18. Melby SJ, Zierer A, Kaiser SP, Schuessler RB, Damiano RJ Jr. Epicardial microwave ablation on the beating heart for atrial fibrillation: the dependency of lesion depth on cardiac output. $J$ Thorac Cardiovasc Surg. 2006;132:355-60.

19. Pruitt JC, Lazzara RR, Ebra G. Minimally invasive surgical ablation of atrial fibrillation: the thoracoscopic box lesion approach. J Interv Card Electrophysiol. 2007;20:83-7.

20. Bevilacqua S, Gasbarri T, Cerillo AG, Mariani M, Murzi M, Nannini T, et al. A new vacuum-assisted probe for minimally invasive radiofrequency ablation. Ann Thorac Surg. 2009;88:1317-21.

21. McCarthy PM, Kruse J, Shalli S, Ilkhanoff L, Goldberger JJ, Kadish AH, et al. Where does atrial fibrillation surgery fail? Implications for increasing effectiveness of ablation. J Thorac Cardiovasc Surg. 2010;139:860-7.

22. Miyagi Y, Ishii Y, Nitta T, Ochi M, Shimizu K. Electrophysiological and histological assessment of transmurality after epicardial ablation using unipolar radiofrequency energy. J Card Surg. 2009;24:34-40.

23. Soni LK, Cedola SR, Cogan J, Jiang J, Yang J, Takayama H, et al. Right atria lesions do not improve the efficacy of a complete left atrial lesion set in the surgical treatment of atrial fibrillation, but they do increase procedural morbidity. J Thorac Cardiovasc Surg. 2013;145:356-63. 